\title{
Pulmonary Nocardiosis Presenting as Exacerbation of Chronic Pulmonary Disease
}

\author{
Roopa Kancherla ${ }^{1}$, Ramanathan Palaniappan Ramanathan ${ }^{2}$, Bobbe Appalaraju ${ }^{3}$, Srinivas Rajagopala ${ }^{4}$
}

\begin{abstract}
Background: Pulmonary nocardiosis (PN) occurs in chronic pulmonary disease (CPD) in the absence of traditional risk factors. Clinical features that differentiate bacterial exacerbations $\left(A E-C P D_{b}\right)$ from PN-related exacerbations $\left(A E-C P D_{P N}\right)$ are not well described.

Objectives: To describe a series of $A E-C P D_{P N}$ without traditional risk factors and compare clinical features, radiology and outcomes with age, gender and CLD-type matched $A E-C P D_{b}$.

Materials and methods: Single-center retrospective review and case-control study.

Results: $A E-C P D_{P N}$ had longer duration of symptoms and more leukocytosis at hospitalization. $A E-C D_{b}$ patients were sicker with more chronic respiratory failure (OR 33.3, $p=0.01)$, cardiac disease and pulmonary hypertension $(\mathrm{OR} 6.2, p=0.008)$ at diagnosis. More patients with $A E-C P D_{b}$ were discharged on domiciliary oxygen (OR 5.27, $p=0.01$ ). On logistic regression, $A E-C P D_{P N}$ was independently associated with mechanical ventilation (OR 22.3, $p=0.01$ ), length of hospital stay (median difference, 4 days, $p=0.016$ ) but not to hospital mortality. $22.7 \%$ of $A E-C P D_{P N}$ died. Respiratory failure requiring oxygen, NIPPV or mechanical ventilation was associated with mortality in AE-CPD $D_{\mathrm{PN}}$.

Conclusion: $\mathrm{PN}$ is a rare cause of $\mathrm{AE}-\mathrm{CPD}$ and can be suspected by longer symptom duration, more leukocytosis, consolidation and cavitation. $A E-C P D_{P N}$ is associated with longer hospital stay and mechanical ventilation. Respiratory failure is associated with mortality in $A E-C P D_{P N}$.

Key messages:

- Pulmonary nocardiosis can present in advanced chronic lung disease as an exacerbation in the absence of traditional risk factors like immunosuppression.

- Bronchiectasis, followed by chronic obstructive pulmonary disease are the most common chronic lung disease risk factors.

- Pulmonary nocardiosis is a rare cause of acute exacerbation of chronic pulmonary disease (CPD).

- Compared to exacerbations of CPD due to bacterial infections, nocardiosis-related exacerbations $\left(C D_{P N}\right)$ were independently related to need for mechanical ventilation and length of hospital stay.

- Respiratory failure requiring oxygen, noninvasive ventilation and mechanical ventilation are associated with mortality in $A E-C P D_{P N}$.

Indian Journal of Critical Care Medicine (2019): 10.5005/jp-journals-10071-23270
\end{abstract}

\section{INTRODUCTION}

Acute exacerbation of chronic pulmonary disease (AE-CPD) leads to substantial worsening in quality of life, need for additional therapies, morbidity, mortality and costs. ' Severe exacerbations are associated with respiratory failure, need for mechanical ventilation and mortality. ${ }^{2}$ Pulmonary nocardiosis, the most frequent presentation of human infection by Nocardia spp, is increasingly being recognized in patients with CPDs, including chronic obstructive pulmonary disease (COPD). ${ }^{3}$ Predisposing factors include bacterial colonization of lower airways with advanced lung disease, oral steroid use for exacerbations and structural lung disease in the form of associated bronchiectasis in severe COPD. ${ }^{4}$ Most series of PN in CPDs include patients with associated traditional predisposing factors like steroid therapy, solid-organ or hematopoietic cell transplantation, human immunodeficiency virus infection or malignancy; mortality determinants were thus affected by these associated risk factors. ${ }^{4}$ The clinical features, radiologic findings, laboratory clues that should suggest the presence of PN in $A E-C P D\left(A E-C P D_{P N}\right)$ and its outcomes are not well described. We describe a series of $A E-C P D_{P N}$ in the absence of traditional risk factors to determine clinical features that can distinguish it from bacterial exacerbations of CPD $\left(A E-C P D_{b}\right)$ and determine the association of $A E-C P D_{P N}$ with need for mechanical ventilation, hospital length of stay and mortality.

\footnotetext{
1,2,4 Department of Pulmonology, PSG Institute of Medical Sciences and Research, Peelamedu, Coimbatore, Tamil Nadu, India

${ }^{3}$ Department of Microbiology, PSG Institute of Medical Sciences and Research, Peelamedu, Coimbatore, Tamil Nadu, India
}

Corresponding Author: Srinivas Rajagopala, Department of Pulmonology, PSG Institute of Medical Sciences and Research, Peelamedu, Coimbatore, Tamil Nadu, India, Phones: 91-422-2570170, 91-422-2598822, e-mail: visitsrinivasan@gmail.com

How to cite this article: Kancherla R, Ramanathan RM PL, Appalaraju B, Srinivas R. Pulmonary Nocardiosis Presenting as Exacerbation of Chronic Pulmonary Disease. Indian J Crit Care Med 2019;23(10):467474.

Source of support: Nil

Conflict of interest: None

\section{Materials and Methods}

This is a retrospective study of patients $\geq 18$ years and a final diagnosis of PN and AE-CPD from a large tertiary care hospital in southern India over 10 years between January 2008 and December 2017. All cases with PN were identified by an electronic search of our records and cross-referenced by a simultaneous manual search of the nocardiosis register in the department of microbiology. Clinical records of all identified cases were retrieved. Only PN presenting

() The Author(s). 2019 Open Access This article is distributed under the terms of the Creative Commons Attribution 4.0 International License (https://creativecommons. org/licenses/by-nc/4.0/), which permits unrestricted use, distribution, and non-commercial reproduction in any medium, provided you give appropriate credit to the original author(s) and the source, provide a link to the Creative Commons license, and indicate if changes were made. The Creative Commons Public Domain Dedication waiver (http://creativecommons.org/publicdomain/zero/1.0/) applies to the data made available in this article, unless otherwise stated. 
Flowchart 1: Number of enrolled patients in the study

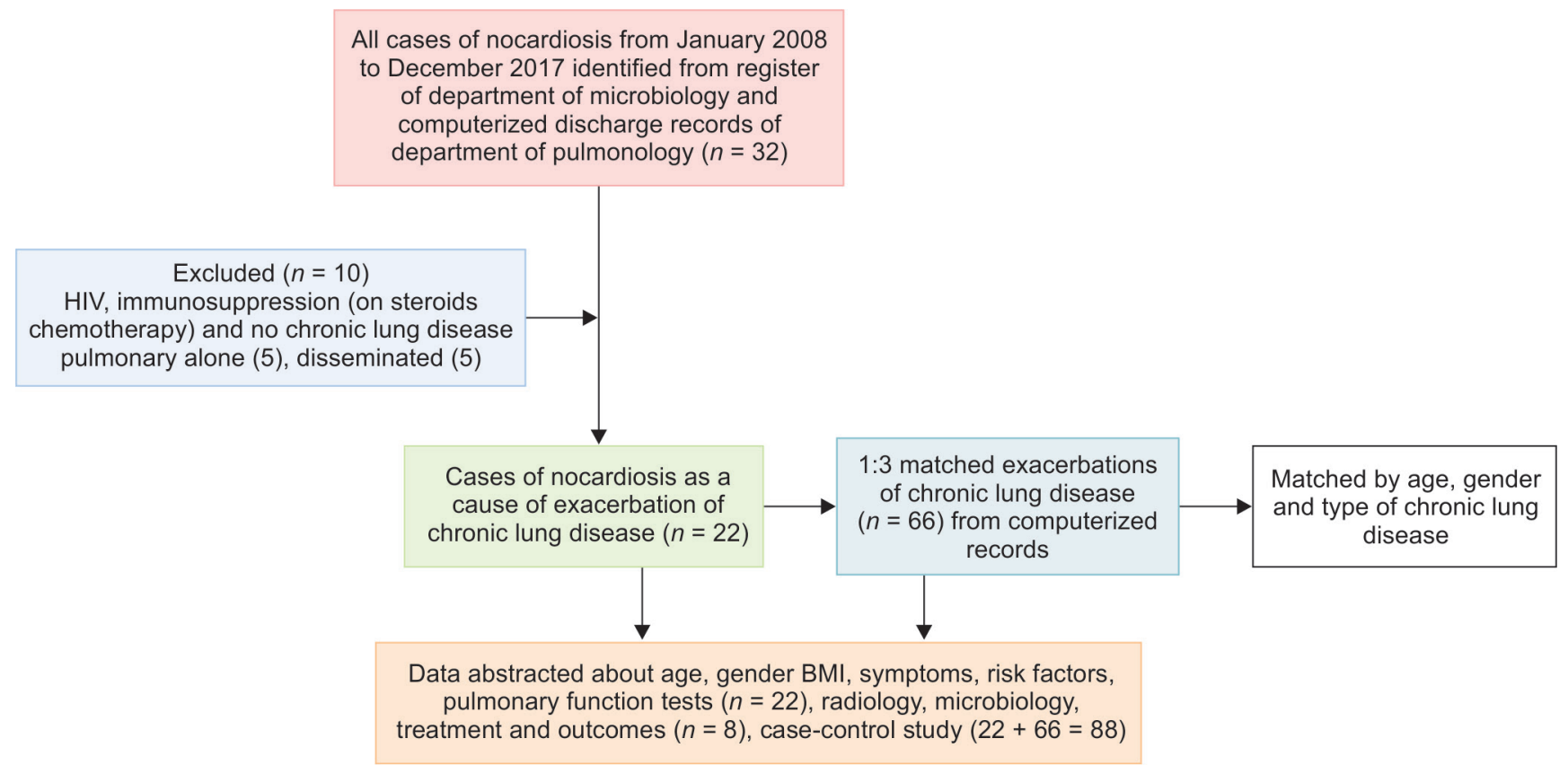

with worsening of underlying CPD was included. PN associated with long-term steroid therapy, immunosuppressive therapy, human immunodeficiency infection (HIV) and malignancy and PN in the absence of CPD was excluded (Flowchart 1).

\section{Study Subjects}

\section{Case Series}

CPD was defined by the presence of one of the following conditions; COPD, bronchial asthma, bronchiectasis, interstitial lung disease (ILD) and post-tuberculosis lung disease. The diagnosis of COPD, bronchial asthma, bronchiectasis and ILD was made according to standard guidelines. ${ }^{1,5,6}$ The diagnosis of obstruction and restriction on spirometry was according to ATS/ERS guidelines. ${ }^{7}$ An exacerbation of CPD was defined as worsening of respiratory symptoms that resulted in additional therapy. ${ }^{1}$ If the initial diagnosis of CPD was made during an exacerbation of CPD, spirometry performed subsequently during stable disease, where available, was taken for data abstraction. PN was diagnosed on the basis of (i) presence of compatible respiratory symptoms and (ii) isolation of Nocardia spp. in smears and/or cultures of respiratory samples or (iii) histopathology of transthoracic or bronchoscopic biopsies showing organisms consistent with Nocardia spp..$^{8}$ Respiratory samples included sputum, endotracheal aspirates, bronchoalveolar lavage fluid (BALF) and pleural fluid. Nocardiosis was diagnosed as "disseminated" if there was isolation in blood culture or demonstrable infection in other organs, including skin and central nervous system in association with respiratory infection. ${ }^{8}$ Recent steroid intake was defined as steroid intake in the 3 months prior to diagnosis of PN. We excluded any patient with steroid intake $>7.5$ $\mathrm{mg}$ in 3 months prior to the diagnosis of pulmonary nocardiosis to eliminate oral steroid as a confounding factor for $A E-C P D_{P N}$. Chronic respiratory failure was defined by an arterial blood gas (ABG) with $\mathrm{PaO}_{2} \leq 55 \mathrm{~mm} \mathrm{Hg}$ or $<60 \mathrm{~mm} \mathrm{Hg}$ in the presence of pulmonary hypertension; $\mathrm{PaCO}_{2} \geq 45 \mathrm{~mm} \mathrm{Hg}$ with or without $\mathrm{pH} \leq 7.36$ in the absence of symptoms suggestive of an acute deterioration., ${ }^{1,9}$

\section{Controls}

Controls were patients with COPD, bronchiectasis, post-tuberculosis lung disease and ILD without any Immunocompromising condition, including receipt of steroids in 3 months prior to study inclusion. Only exacerbations that were microbiologically proven or clinically presumed to be due to bacterial infection $\left(A E-C P D_{b}\right)$ were included. Receipt of antibiotics was taken as a surrogate for clinical presumption of infection; any controls with suspected or proven exacerbations due to viral infections, heart failure or pulmonary embolism were excluded. Patients with a presumed bacterial infection were included only if they had a complete clinical response to antibiotics and supportive care alone; outpatient follow-up notes and radiology were retrieved and reviewed for all controls for confirmation. Controls with exacerbations and radiological infiltrates were included in an attempt to match illness severity between cases and controls. Three controls were identified for each case and matched by age, gender and type of chronic lung disease.

\section{Microbiological Identification}

Samples collected included sputum, endotracheal aspirates, BALF and pleural fluid under sterile precautions. The samples were examined by direct microscopy after Gram's staining to establish specimen quality. Modified Kinyoun's stain was also done if nocardiosis was suspected clinically or if Gram's stain showed organisms compatible with Nocardia spp. All samples were then homogenized with sterile glass beads in a test tube and incubated in blood agar and Sabouraud's dextrose agar at $37^{\circ} \mathrm{C}$ in an aerobic atmosphere for up to 4 weeks and examined every alternate day for growth. The presumptive identification of Nocardia spp. was based on the microscopy showing branching gram-positive thin filamentous rods (Fig. 1A), partially acid-fast with modified Kinyoun's stain (Fig. 1B) and the macroscopic morphology of buff or pigmented waxy cerebriform colonies. Identification at the species level was done using biochemical testing. From 2019 onwards, 16s rRNA based-DNA sequencing was implemented for speciation (outside study period). 

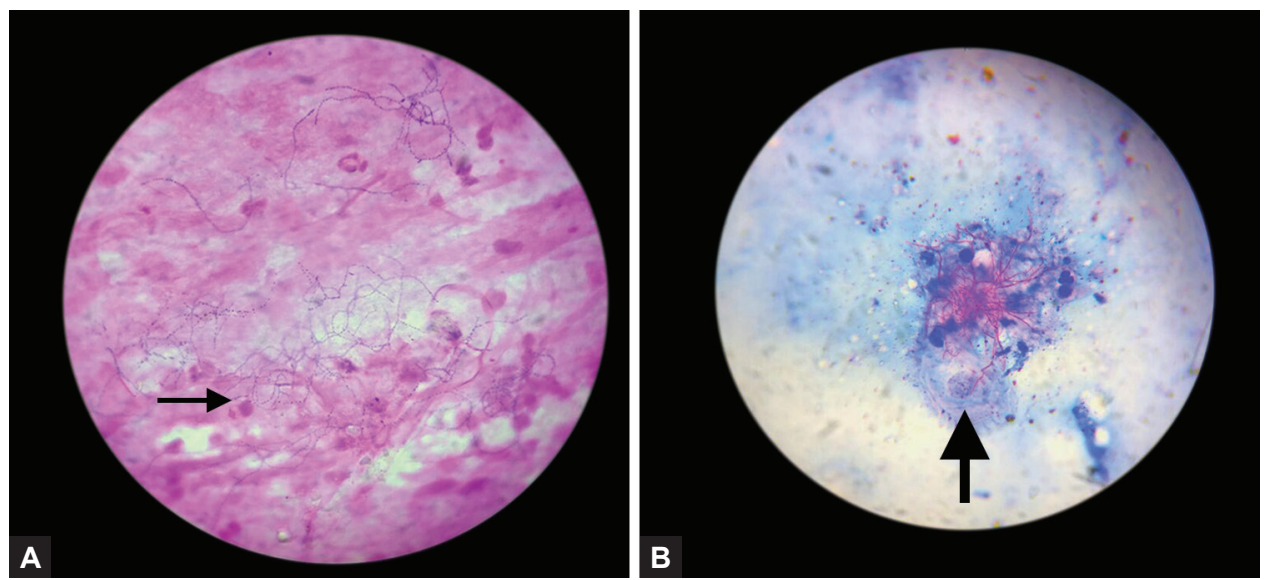

Figs $1 \mathrm{~A}$ and B: Composite image with Gram's staining of sputum sample. (A) Branching of gram-positive thin filamentous organisms consistent with Nocardia spp; (B) Modified acid-fast staining confirmed that these organisms were acid-fast

\section{Treatment Protocol for PN}

All admitted patients received meropenem $1 \mathrm{~g}$ every 8 hours for 2-4 weeks, along with oral or parenteral cotrimoxazole $(15 \mathrm{mg} / \mathrm{kg}$ trimethoprim equivalent in three divided doses); cotrimoxazole alone was then continued for the remaining duration of 6 months. All patients with PN were admitted only till clinical stabilization as defined by absence of fever, normal hemodynamics and need for minimal or no oxygen; parenteral antibiotics were continued on ambulatory basis or arranged at a center of convenience for the prescribed period. In mild PN treated as outpatient basis, cotrimoxazole alone $(10 \mathrm{mg} / \mathrm{kg}$ trimethoprim equivalent in three divided doses) was administered. In cases of suspected or proven disseminated nocardiosis, amikacin $15 \mathrm{mg} / \mathrm{kg}$ was added for the initial period and the initial intensive phase was extended from four to 6 weeks. ${ }^{10,11}$

\section{Data Extraction}

Data was abstracted in a predefined data extraction form. From the selected cases, the following data were gathered: (a) demographic details of each case including age and gender, (b) duration of symptoms, (c) symptoms at presentation, (d) type of chronic lung disease, (e) body mass index, (f) co-morbidities and their details, including smoking, alcohol abuse, diabetes, chronic kidney disease, steroid receipt in the last 6 months before diagnosis and concurrent malignancy, (g) diagnosis of chronic respiratory failure before the diagnosis of PN, (h) spirometry values, (i) laboratory investigations, including total leukocyte counts, arterial blood gas analysis, (j) radiologic findings and echocardiography, $(\mathrm{k})$ microbiologic isolates, (I) treatment administered, including details of steroids, antimicrobial therapy and their duration, oxygen use, noninvasive or invasive ventilation and its duration, and ( $\mathrm{m}$ ) outcomes; discharge on domiciliary oxygen and hospital mortality.

\section{Outcome Measures}

The duration of symptoms prior to presentation, symptoms, laboratory findings, radiologic findings, treatment administered and outcomes were compared between patients with $A E-C P D_{b}$ and $A E-C P D_{P N}$

\section{Statistics}

Statistical analyses were performed using SPSS version 14. Continuous variables were described in a descriptive fashion (mean $\pm S D$, median, IQR) and discrete variables were described as frequency proportions. Comparisons for continuous variables were performed using the independent T test or Mann-Whitney test and proportions using the Chi-square test or Fisher's exact test, where appropriate. Statistical significance was assessed at the 2 -sided $p \leq$ 0.05 level. The independent association of $A E-C P D_{P N}$ with the need for noninvasive or invasive mechanical ventilation and mortality was tested by logistic regression.

\section{Ethics}

The Research Ethics Committee of our Hospital approved this study. All data abstracted was anonymized, thus ensuring confidentiality and patient privacy.

\section{Results}

There were a total of 32 cases of PN over a 10-year period. We excluded 10 cases, including five with disseminated nocardiosis without coexisting CPD. There were a total of 22 cases of $A E-C P D_{P N}$ including 13 men and 9 women; all had localized pulmonary disease. The type of CPD was most commonly bronchiectasis $(59 \%, 13 / 22)$, followed by COPD $(36.4 \%, 8 / 22)$ and ILD $(1 / 22,4.5 \%)$ (Table 1A). Bronchiectasis was cystic (CB) and multilobar in all and the etiology was idiopathic, post-tuberculosis or allergic bronchopulmonary aspergillosis (ABPA)-related. 21/22 of $A E-C P D_{P N}$ had inhaled corticosteroids (ICS) use compared to $63 / 66$ of the controls; these were patients with advanced airway disease and were on triple therapy and ICS use was not different in cases compared to controls. The final $22 \mathrm{AE}-\mathrm{CPD}_{\mathrm{PN}}$ included did not have any oral steroid intake in the 12 months prior to the diagnosis of PN. The patient with $A E-C P D_{P N}$ related to ILD was steroid-naïve and the diagnosis of ILD was made concurrent with the diagnosis of PN. Two patients with $A E-C P D_{P N}$ received steroids for severe bronchospasm with a diagnosis of $A E-C P D_{b}$ before the diagnosis of $P N$; in both, steroids were discontinued after diagnosis Among patients with $\mathrm{AE}-\mathrm{CPD}_{\mathrm{b}}$, Pseudomonas aeruginosa was the most common organism isolated. $27.2 \%(6 / 22)$ of the patients with $A E-C P D_{P N}$ had a presumed or proven bacterial coinfection. All patients with $A E-C P D_{P N}$ were treated with cotrimoxazole for a median (IQR) duration of 6(2) months. Two patients were subsequently treated with other regimens after discontinuation of cotrimoxazole; reasons included inability to tolerate cotrimoxazole due to persistent severe hyperkalemia and in another, the isolate was reported as $N$. farcinica resistant to cotrimoxazole in association with clinical failure. 
Table 1A: Comparison between patients with exacerbations of chronic lung disease due to Nocardia and bacterial exacerbations of chronic lung disease

\begin{tabular}{|c|c|c|c|}
\hline Characteristics & $\begin{array}{l}\text { Nocardia related exacerbation } \\
(n=22)\end{array}$ & Bacterial exacerbations $(n=66)$ & $P$ value, ${ }^{* *} \mathrm{OR} 95 \% \mathrm{Cl}$ \\
\hline Age years, mean $\pm S E$ & $61.36 \pm 2.9$ & $60.5 \pm 1.7$ & 0.79 \\
\hline Gender, male: female & 13:9 & $39: 27$ & 1.00 \\
\hline $\begin{array}{l}\text { Etiology of chronic lung disease } \\
\text { before diagnosis }\end{array}$ & $\begin{array}{l}\text { COPD (8/22), BXSIS (13/22), ILD } \\
(1 / 22)\end{array}$ & $\begin{array}{l}\text { COPD (24/66), Bronchiectasis } \\
(39 / 66), \text { ILD }(3 / 66)\end{array}$ & 1.00 \\
\hline $\begin{array}{l}\text { Body mass Index } \mathrm{kg} / \mathrm{m}^{2} \\
\text { mean } \pm \mathrm{SE}\end{array}$ & $18.6 \pm 1.2$ & $21.3 \pm 0.9$ & 0.08 \\
\hline \multicolumn{4}{|l|}{ Risk factors } \\
\hline & $\begin{array}{l}\text { Smoking }(8 / 22,36.4 \%) \text {, alcohol } \\
\text { abuse }(3 / 22,13.6 \%)\end{array}$ & $\begin{array}{l}\text { Smoking }(28 / 66,42.4 \%) \text {, alcohol } \\
\text { abuse }(8 / 66,12.1 \%)\end{array}$ & N.S \\
\hline & $\begin{array}{l}\text { *Recent steroid intake }(2 / 22 \text {, } \\
9.1 \%)\end{array}$ & Recent steroid intake $(6 / 66,9.1 \%)$ & 1.00 \\
\hline & Diabetes $(6 / 22,27.2 \%)$ & Diabetes (16/66, 24.2\%) & N.S \\
\hline & Prior tuberculosis $(9 / 22,40.9 \%)$ & Prior tuberculosis $(14 / 66,21.2 \%)$ & 0.08 \\
\hline \multicolumn{4}{|l|}{ Symptoms at presentation } \\
\hline Fever & $10 / 22(45.4 \%)$ & 19/66 (43.9\%) & 0.07 \\
\hline Cough & $20 / 22(90.9 \%)$ & $60 / 66(90.9 \%)$ & 0.83 \\
\hline Dyspnea & $16 / 22(72.7 \%)$ & $61 / 66(92.4 \%)$ & OR $0.17(0.04-0.69), p=0.01$ \\
\hline $\begin{array}{l}\text { Chronic respiratory failure } \\
\text { before diagnosis }\end{array}$ & $0 / 22(0 \%)$ & $28 / 66(42.4 \%)$ & OR $0.03(0.0-0.51), p<0.001$ \\
\hline $\begin{array}{l}\text { Duration before presentation, } \\
\text { days (Median, IQR) }\end{array}$ & $12,(23)$ & $7,(8)$ & 0.001 \\
\hline \multicolumn{4}{|l|}{ Spirometry } \\
\hline $\mathrm{FEV} / \mathrm{FVC} \%$, mean $\pm \mathrm{SE}$ & $68 \pm 7.23$ & $63.2 \pm 4.95$ & 0.65 \\
\hline FEV1 L, \% mean \pm SE & $1.01 \pm 0.05 \mathrm{~L}, 53.6 \pm 2.4 \%$ & $1.1 \pm 0.1 \mathrm{~L}, 45.4 \pm 4.9 \%$ & 0.71 \\
\hline FVC L, \% mean \pm SE & $1.5 \pm 0.1 \mathrm{~L}, 58.0 \pm 2.1 \%$ & $1.7 \pm 0.2 \mathrm{~L}, 54.4 \pm 5.8 \%$ & 0.55 \\
\hline $\begin{array}{l}\text { Total leukocyte count } / \mu \mathrm{L} \text {, } \\
\text { Mean } \pm \mathrm{SE}\end{array}$ & $17985 \pm 228 / \mu \mathrm{L}$ & $12426 \pm 65 / \mu \mathrm{L}$ & 0.002 \\
\hline $\begin{array}{l}\text { N\%, Absolute neutrophil count/ } \\
\mu \mathrm{L} \text {, mean } \pm \text { SE }\end{array}$ & $83.6 \pm 2.8 \%, 14420 \pm 238 / \mu \mathrm{L}$ & $78.6 \pm 1.4 \%, 10027 \pm 63 / \mu \mathrm{L}$ & 0.01 \\
\hline Hemoglobin $\mathrm{g} / \mathrm{dL}$, mean $\pm \mathrm{SE}$ & $11.8 \pm 0.4$ & $12.4 \pm 0.2$ & 0.24 \\
\hline $\begin{array}{l}\text { Erythrocyte sedimentation rate } \\
\mathrm{mm} / \mathrm{hr} \text {, mean } \pm \mathrm{SE}\end{array}$ & $62.2 \pm 5.9$ & $37.1 \pm 3.3$ & $<0.001$ \\
\hline Renal failure at diagnosis & $2 / 22(9.1 \%)$ & $22 / 66(33.3 \%)$ & OR $0.2(0.04-0.9), p=0.02$ \\
\hline \multicolumn{4}{|l|}{ Arterial blood gas at diagnosis } \\
\hline $\mathrm{pH}$, mean $\pm \mathrm{SE}$ & $7.43 \pm 0.01$ & $7.36 \pm 0.01$ & 0.016 \\
\hline $\mathrm{paO}_{2} \mathrm{~mm} \mathrm{Hg}$, mean $\pm \mathrm{SE}$ & $73.2 \pm 5.3$ & $88.8 \pm 4.9$ & 0.14 \\
\hline $\mathrm{paCO}_{2} \mathrm{~mm} \mathrm{Hg}$, mean $\pm \mathrm{SE}$ & $38.9 \pm 3.3$ & $51.6 \pm 2.2$ & 0.013 \\
\hline $\mathrm{HCO}_{3} \mathrm{mEq} / \mathrm{L}$, mean $\pm \mathrm{SE}$ & $25.0 \pm 1.5$ & $28.3 \pm 0.8$ & 0.06 \\
\hline
\end{tabular}

There was no difference in body-mass index, lung function at baseline, presence of obstruction on spirometry, presence of risk factors like smoking, alcohol abuse, recent steroid intake, diabetes or prior tuberculosis between $\mathrm{AE}-\mathrm{CPD}_{\mathrm{b}}$, and $\mathrm{AE}-\mathrm{CPD}_{\mathrm{PN}}$ (Table 1B). When compared to age, gender and type of CPD-matched $A E-C P D_{b}$, $\mathrm{AE}-\mathrm{CPD}_{\mathrm{PN}}$ had longer symptom duration (median difference 5 days, $p=0.014$ ) prior to presentation. There was more leukocytosis (mean difference 5559/ $\mu \mathrm{L}, p=0.002$ ), neutrophilia (mean difference 4373/ $\mu \mathrm{L}, p=0.01$ ) and higher erythrocyte sedimentation rate (mean difference $25.1 \mathrm{~mm} /$ hour, $p<0.001$ ) at hospitalization. Patients with $A E-C P D_{b}$ had higher proportion with dyspnea at presentation (OR 4.57, $p=0.02$ ), chronic respiratory failure prior to diagnosis of bacterial exacerbation (OR 33.3, $p=0.01$ ), and more respiratory acidosis ( $\mathrm{pH}$ difference $-0.04, p=0.016, \mathrm{PaCO}_{2}$ difference $12.7 \mathrm{~mm}$ $\mathrm{Hg}, p=0.01$ ) at diagnosis. More patients with $\mathrm{AE}-\mathrm{CPD}_{\mathrm{b}}$ had acute kidney injury (AKI, O.R 5.0, 95\% Cl 1.07-23.3, $p=0.04$ ) at diagnosis, with $22.7 \%(5 / 22)$ requiring dialysis. Two patients with $A E-C P D_{P N}$ had renal failure, with both requiring dialysis. There was also higher proportion of left ventricular systolic or diastolic dysfunction (OR $5.27,95 \% \mathrm{Cl} 1.34-20.7, p=0.01$ ) and pulmonary hypertension (OR $6.2, p=0.008)$ in patients with $\mathrm{AE}-\mathrm{CPD}_{\mathrm{b}}$.

On imaging, $A E-C P D_{P N}$ had higher proportion of consolidation (95.5\%) and cavitation (27.3\%). Consolidation was mass-like, multilobar or multifocal in all patients with $A E-C P D_{P N}$. (Figs 2 and 3). On univariate analysis, there was no difference in the need for oxygen, noninvasive ventilation or mechanical ventilation between 
Table 1B: Comparison of findings and clinical course between patients with exacerbations of chronic lung disease due to Nocardia and bacterial exacerbations of chronic lung disease

\begin{tabular}{|c|c|c|c|}
\hline Characteristics & Nocardia related exacerbation & Bacterial exacerbations & $P$ value, OR 95\% Cl \\
\hline Arterial blood gas at presentation & $\begin{array}{l}\text { Hypoxemia ( } 69.2 \%) \text {, type } 1 \\
\text { (23.1\%), type } 2 \text { failure }(7.7 \%)\end{array}$ & $\begin{array}{l}\text { Hypoxemia ( } 28.6 \%) \text {, type } 1 \\
(16.1 \%) \text {, type } 2 \text { failure (55.4\%) }\end{array}$ & $\begin{array}{l}* * \text { OR } 0.05,(0.007-0.44) \\
p=0.006\end{array}$ \\
\hline \multicolumn{4}{|l|}{ Radiological findings at diagnosis } \\
\hline Consolidation & $21 / 22(95.5 \%)$ & $53 / 66(80.3 \%)$ & 0.06 \\
\hline Cavitation & $6 / 22(27.3 \%)$ & $4 / 66(6.1 \%)$ & $5.81(1.46-23.1), p=0.01$ \\
\hline Pleural effusion & $2 / 22(9.1 \%)$ & $2 / 66(3 \%)$ & 0.26 \\
\hline \multicolumn{4}{|l|}{ Cardiac findings } \\
\hline Cardiac disease & $\operatorname{LVSD}(0 / 17), \operatorname{LVDD}(3 / 17,17.6 \%)$ & $\begin{array}{l}\operatorname{LVSD}(5 / 49,10.2 \%), \operatorname{LVDD}(21 / 49 \\
42.8 \%)\end{array}$ & OR $0.18(0.04-0.74), p=0.01$ \\
\hline Pulmonary hypertension & $3 / 17(17.6 \%)$ & $28 / 49(57.1 \%)$ & OR $0.16(0.04-0.63), p=0.008$ \\
\hline \multicolumn{4}{|l|}{ Microbiological evaluation } \\
\hline Etiology of exacerbations & $\begin{array}{l}\text { Nocardia }(22 / 22,100 \%) \text {, bacterial } \\
\text { coinfections }(6 / 22,27.2 \%)\end{array}$ & $\begin{array}{l}\text { No growth }(49 / 66,74.3 \%) \text {, } \\
\text { Pseudomonas } 9 / 66(13.6 \%) \text {, } \\
\text { others }(6 / 66,9.1 \%)\end{array}$ & NA \\
\hline \multicolumn{4}{|l|}{ Treatment details } \\
\hline $\begin{array}{l}\text { New respiratory failure needing } \\
\text { oxygen }\end{array}$ & $9 / 22(40.9 \%)$ & $21 / 66(33 \%)$ & O.R $1.48, p=0.44$ \\
\hline $\begin{array}{l}\text { Oxygen duration days, median, } \\
\text { IQR }\end{array}$ & $5(10.75)$ & $5(3)$ & 0.50 \\
\hline NIPPV & $5 / 22(22.7 \%)$ & $23 / 66(34.8 \%)$ & 0.28 \\
\hline $\begin{array}{l}\text { NIPPV duration days, median, } \\
\text { IQR }\end{array}$ & $4(7)$ & $6(2.5)$ & 0.29 \\
\hline Mechanical ventilation & $5 / 22(22.7 \%)$ & $6 / 66(9.1 \%)$ & O.R $2.94(0.79-10.8), p=0.10$ \\
\hline $\begin{array}{l}\text { Mechanical ventilation duration } \\
\text { days, median, IQR }\end{array}$ & $2(5.75)$ & $3.5(1.75)$ & 0.32 \\
\hline $\begin{array}{l}\text { Hospital length of stay days, } \\
\text { Median, IQR }\end{array}$ & $8(9)$ & $5(4)$ & 0.016 \\
\hline Antibiotic receipt & $\begin{array}{l}\text { Cotrimoxazole }(20 / 22) \\
\text { minocycline }(1 / 22) \text {, others }(1 / 22)\end{array}$ & $\begin{array}{l}\text { Penicillins }(29 / 66,43.9 \%), \\
\text { Cephalosporins }(25 / 66,37.8 \%) \text {, } \\
\text { FQ }(8 / 66,12.1 \%)\end{array}$ & NA \\
\hline $\begin{array}{l}\text { Duration of cotrimoxazole } \\
\text { months median, IQR }\end{array}$ & $6(2)$ & NA & NA \\
\hline Steroids during exacerbation & $2 / 22(9.1 \%)$ & $26 / 66(39.4 \%)$ & OR $0.15(0.03-0.71), p=0.01$ \\
\hline Discharged on home oxygen & $3 / 17(17.6 \%)$ & $35 / 66(53 \%)$ & OR $0.18(0.04-0.72), p=0.01$ \\
\hline Alive at hospital discharge & $17 / 22(77.3 \%)$ & $66 / 66(100 \%)$ & OR $41.8(2.2-792.7), p=0.01$ \\
\hline
\end{tabular}

**Odds ratios are presented for significant associations

$\mathrm{N} \%$, percentage of neutrophils; COPD, chronic obstructive pulmonary disease; ILD, interstitial lung disease; $\mathrm{pH}$, inverse log of proton concentration; $\mathrm{PaO}_{2}$, partial pressure of oxygen; $\mathrm{PaCO}_{2}$, partial pressure of carbon dioxide; $\mathrm{HCO}_{3}$, serum bicarbonate; LVSD, left ventricular systolic dysfunction; LVDD, left ventricular diastolic dysfunction; ASD, atrial septal defect; PH, pulmonary hypertension; * $\leq 3$ months from diagnosis; NIPPV, noninvasive positive pressure ventilation; $\mathrm{FQ}$, fluoroquinolone; $\mathrm{SD}$, standard deviation; $\mathrm{QQR}$, interquartile range; $\mathrm{OR}$, odds ratio; $\mathrm{Cl}$, confidence interval

$\mathrm{AE}-\mathrm{CPD}_{\mathrm{PN}}$ and $\mathrm{AE}-\mathrm{CPD}_{\mathrm{b}}$. Patients with $\mathrm{AE}-\mathrm{CPD}_{\mathrm{PN}}$ had a longer stay for clinical stabilization $(p=0.016)$ and more patients with $A E-C P D_{b}$ were discharged on domiciliary oxygen (O.R 5.27, $p=0.01$ ). On multiple logistic regression, after adjusting for higher illness severity of $A E-C P D_{b}, A E-C P D_{P N}$ was independently related to need for mechanical ventilation (OR 22.3, $p=0.01$ ), length of hospital stay (median difference, 4 days, $p=0.016$ ) but not to hospital mortality (Table 2).

$A E-C P D_{P N}$ was associated with a $22.7 \%(5 / 22)$ mortality. There was no difference in recent receipt of steroids prior to diagnosis of $\mathrm{PN}$, renal failure at diagnosis, $\mathrm{pH}$ or hospital stay between survivors and nonsurvivors (Table 3). Respiratory failure requiring oxygen, NIPPV or mechanical ventilation was associated with mortality in $A E-C P D_{P N}$.

\section{Discussion}

Pulmonary nocardiosis is a rare thoracic infection predominantly affecting immunocompromised hosts. ${ }^{8}$ The traditional risk factors for PN include long-term steroid therapy, malignancy, chemotherapy and HIV infection. ${ }^{11}$ However, one-third of cases reportedly occur in immunocompetent patients. ${ }^{12}$ There is increasing recognition that COPD is a risk factor for PN..$^{13}$ Data are mostly from case reports and small series, given the rarity of PN. ${ }^{3,4,14-16}$ Notably, several of these cases have COPD associated with bronchiectasis and this is an important but under-recognized risk-factor for PN as well. ${ }^{3,13}$ In our series, bronchiectasis was the most common underlying CPD. No clustering of cases was noted and only five of the 22 cases were diagnosed and managed in the outpatient non-CF bronchiectasis 

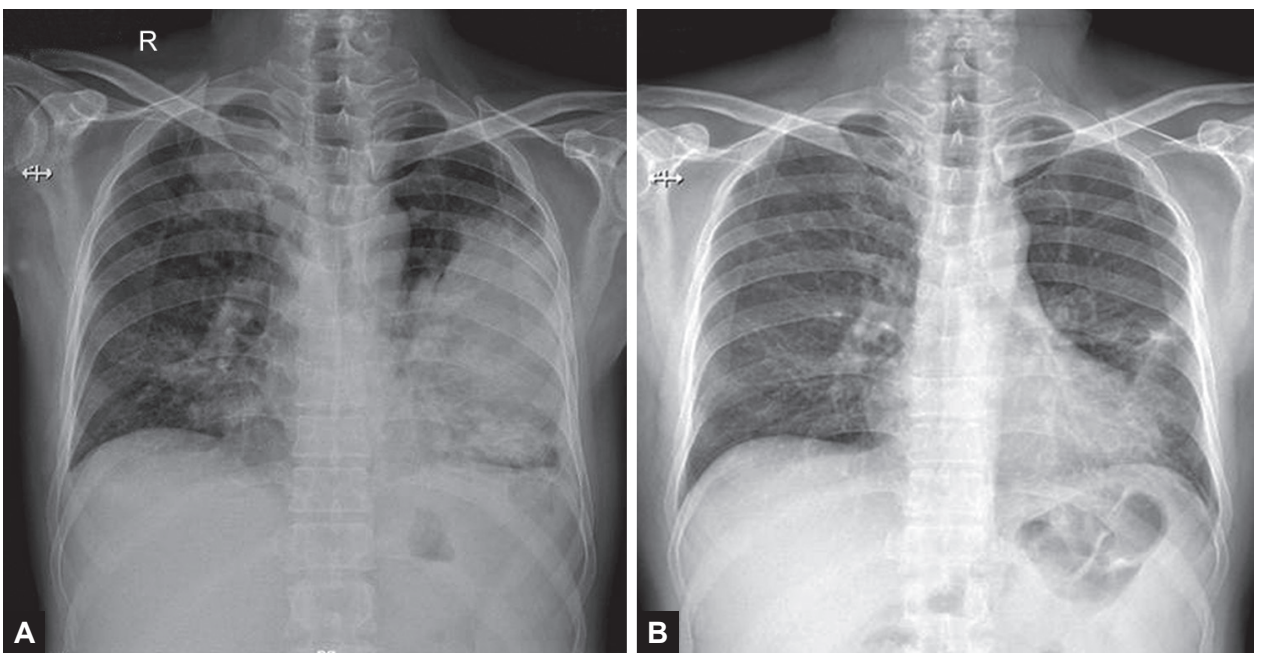

Figs $2 \mathrm{~A}$ and B: Composite image with chest radiograph (A) of a patient with pulmonary nocardiosis-related chronic pulmonary disease exacerbation showing multilobar consolidation, with a dense mass-like consolidation in the left lingula. Bronchoscopic biopsy from lingula confirmed nocardiosis; (B) Repeat chest radiographs at 6 months of cotrimoxazole showed resolution with a small area of residual fibrosis
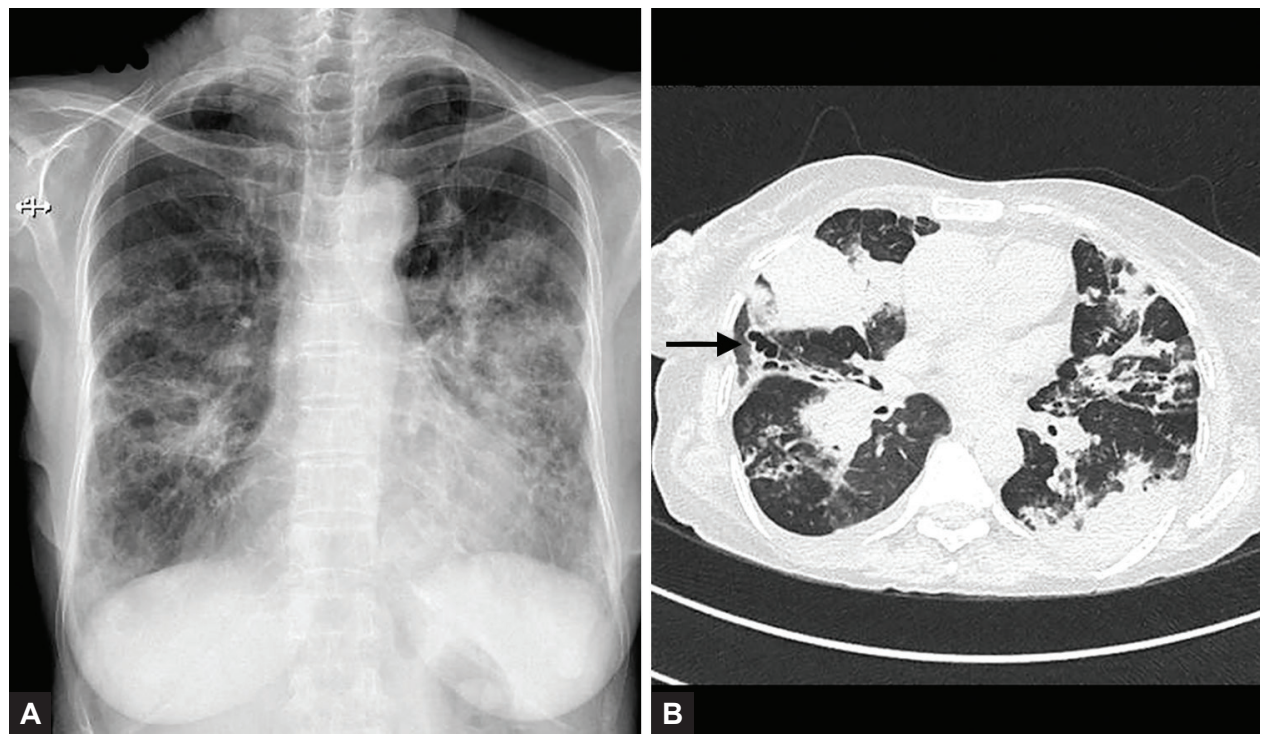

Figs 3A and B: (A) Composite image with chest radiograph of a patient with pulmonary nocardiosis-related chronic pulmonary disease exacerbation showing multilobar consolidation; (B) Computed tomography confirmed extensive consolidation and also showed bronchiectasis (thin arrow)

Table 2A: Univariate logistic regression of the association of Nocardiarelated exacerbations and need for mechanical ventilation

\begin{tabular}{lllll}
\hline & \multicolumn{4}{c}{$\begin{array}{c}\text { Nocardia-related versus bacterial } \\
\text { exacerbation }\end{array}$} \\
\cline { 2 - 5 } & Odds ratio & Lower & Upper & p value \\
\hline Renal failure & 0.2 & 0.043 & 0.93 & 0.041 \\
Respiratory failure & 0.18 & 0.051 & 0.64 & 0.008 \\
$\mathrm{pH}$ (unit change $=0.1$ ) & 3.99 & 1.424 & 15.18 & 0.02 \\
\hline
\end{tabular}

Table 2B: Multiple logistic regression of the association of Nocardiarelated exacerbations and need for mechanical ventilation (*after adjusting for renal failure and respiratory failure before diagnosis)

\begin{tabular}{lllll}
\hline & \multicolumn{3}{c}{ Nocardia-related vs bacterial exacerbation } \\
\cline { 2 - 5 } & Odds ratio & Lower & Upper & p value \\
\hline $\begin{array}{l}\text { Need for mechanical } \\
\text { ventilation }\end{array}$ & 22.34 & 2.04 & 282.3 & $0.01^{*}$ \\
\hline
\end{tabular}

clinic. None of the cases with $\mathrm{AE}-\mathrm{CPD}_{\mathrm{PN}}$ had received long-term steroids before diagnosis, including all the patients with ABPA. In one-third of the cohort, the diagnosis of CPD was made when they presented with AE-CPD.

Thoracic involvement is the most common presentation of PN and is seen in $85 \%$ of cases at presentation. Symptoms are nonspecific and this is especially true with PN presenting in patients with CPD. ${ }^{4,8} \mathrm{PN}$ in CPD presents with an exacerbation of the underlying respiratory symptoms and is often similar to bacterial exacerbations of CPD $\left(A E-C P D_{b}\right){ }^{17}$ In fact, two cases of $P N$ in our series were initially diagnosed as $A E-C P D_{b}$ and improved with antibacterials for AE-CPD; early relapse of symptoms after discontinuation of antibiotics for $A E-C P D_{b}$ (typically seven days in our practice) prompted extensive microbiological evaluation, yielding a diagnosis of $A E-C P D_{P N}$. This study was conducted in this background to identify clinical features that can distinguish $A E-C P D_{P N}$ from $A E-C P D_{b}$. 
Table 3: Comparison of clinical features of AE-CPDPN between survivors and nonsurvivors

\begin{tabular}{|c|c|c|c|}
\hline Characteristic & $\begin{array}{l}\text { Survivors } \\
(n=17)\end{array}$ & $\begin{array}{l}\text { Nonsurvi- } \\
\text { vors }(n=5)\end{array}$ & Statistics \\
\hline Age years, mean \pm S.D & $60.5 \pm 14.9$ & $64.0 \pm 10.7$ & 0.64 \\
\hline Gender males: Total & $9 / 17$ (52.9\%) & $4 / 5(80 \%)$ & 0.36 \\
\hline $\begin{array}{l}\text { Body mass index, } \mathrm{Kg} / \mathrm{m}^{2}, \\
\text { mean } \pm \text { S.D }\end{array}$ & $18.2 \pm 5.2$ & $21.4 \pm 3.4$ & 0.58 \\
\hline $\begin{array}{l}\text { Duration before presenta- } \\
\text { tion, days median, range }\end{array}$ & $12(88)$ & $8(116)$ & 0.57 \\
\hline $\begin{array}{l}\text { Recent steroids ( }<3 \\
\text { months) before diagnosis }\end{array}$ & $2 / 17(11.8 \%)$ & $0 / 5(0 \%)$ & 1.00 \\
\hline Hemoglobin g/dL & $11.5 \pm 2.2$ & $12.8 \pm 1.2$ & 0.27 \\
\hline $\begin{array}{l}\text { Total leukocyte count } / / \mu \mathrm{L} \text {, } \\
\text { Mean } \pm \text { S.E }\end{array}$ & $16462 \pm 2422$ & $\begin{array}{l}22860 \pm \\
5630\end{array}$ & 0.34 \\
\hline $\mathrm{pH}$, Mean \pm S.D & $7.44 \pm 0.06$ & $7.40 \pm 0.05$ & 0.16 \\
\hline $\begin{array}{l}\mathrm{paO}_{2} \text { at diagnosis, Mean } \\
\pm \mathrm{S} . \mathrm{D}\end{array}$ & $73.2 \pm 18.3$ & $73.2 \pm 22.6$ & 1.00 \\
\hline $\begin{array}{l}\text { Chronic respiratory failure } \\
\text { before diagnosis }\end{array}$ & $0 / 17$ & $0 / 5$ & NA \\
\hline Renal failure at diagnosis & $1 / 17(5.9 \%)$ & $1 / 5(20 \%)$ & 0.41 \\
\hline Cavity on chest imaging & 4/17 (23.6\%) & $2 / 5(40 \%)$ & 0.58 \\
\hline Nocardia vs coinfection & $5 / 17(29.5 \%)$ & $1 / 5(20 \%)$ & 1.00 \\
\hline $\begin{array}{l}\text { Respiratory failure needing } \\
\text { oxygen }\end{array}$ & 4/17 (23.6\%) & $5 / 5 /(100 \%)$ & 0.005 \\
\hline NIPPV & $2 / 17(11.8 \%)$ & $3 / 5(60 \%)$ & 0.05 \\
\hline Mechanical ventilation & $2 / 17(11.8 \%)$ & $3 / 5(60 \%)$ & 0.05 \\
\hline $\begin{array}{l}\text { Hospital length of stay days } \\
\text { Median, IQR }\end{array}$ & $10(9)$ & $5(13)$ & 0.25 \\
\hline
\end{tabular}

$\mathrm{SD}$, standard deviation; IQR, interquartile range

We did not find additional risk-factors independent of CPD predisposing to $\mathrm{PN}$ in our series (Tables $1 \mathrm{~A}$ and $1 \mathrm{~B}$ ), again establishing the independent risk of CPD for PN. ${ }^{13} \mathrm{AE}-\mathrm{CPD}_{\mathrm{PN}}$ occurred in patients with advanced lung disease (mean FEV1 $1.01 \pm 0.05 \mathrm{~L}, 53.6 \pm$ $2.4 \%$ predicted) who presented with longer symptom duration, more leukocytosis and inflammatory markers when compared to $A E-C P D_{b}$. Extensive consolidation or cavitation prompted suspicion for $P N$ in AE-CPD and cavitation was seen in $27.3 \%$ at diagnosis. Four patients with $A E-C P D_{b}$ had an initial diagnosis of cavitation; one was related to an exacerbation of COPD related to previous tuberculosis and in another three, underlying bronchiectasis had not been diagnosed and consolidation around cystic bronchiectasis spaces was initially misdiagnosed as cavitation.

The cohort of $A E-C P D_{b}$ was sicker with a higher proportion of cardiac disease, pulmonary hypertension, chronic respiratory failure on long-term oxygen therapy, respiratory acidosis and AKI at presentation. Consequently, more patients with $A E-C P D_{b}$ were treated with oxygen, NIPPV (though statistically non-significant) and were discharged on domiciliary oxygen. After adjustment for the higher illness severity of $A E-C P D_{b}, A E-C P D_{P N}$ was independently related to the need for mechanical ventilation and duration of hospital stay. The in-hospital mortality of $22.7 \%$ in $A E-C P D_{P N}$ is similar to previous published reports of PN. ${ }^{4}$ Respiratory failure requiring oxygen therapy, NIPPV or mechanical ventilation was associated with mortality in $A E-C P D_{P N}$.

Our study has several strengths. This is one of the largest series of PN in immunocompetent CPD till date. In another large series of 30 patients with $\mathrm{PN}-\mathrm{CPD}, 23 \%$ (7/30) were related to chronic steroid therapy, chemotherapy and malignancy. Associated immunecompromise was associated with mortality and this masked the mortality associations of PN-CPD per se. ${ }^{4}$ We also identified a matched cohort of $A E-C P D_{b}$ to identify clinical features that could help in early diagnosis of PN in AE-CPD. There are several limitations of this study. The retrospective nature of the study resulted in an imbalance in the baseline characteristics between cases and controls; controls had more preexisting respiratory failure than cases. $\mathrm{PN}$ is a rare disease and conducting prospective studies is not always feasible. Second, we included patients with consolidation in the control group of $A E-C P D_{b}$. While this is debatable, ${ }^{1,18}$ we aimed at a control group with similar severity of illness to $A E-C P D_{P N}$ and including $A E-C P D_{b}$ with consolidation was considered appropriate as most patients with $A E-C P D_{P N}$ had consolidation at diagnosis. While some reports of $A E-C P D$ exclude those with consolidation, this would have prevented us from identifying clinical features that help in early diagnosis of $A E-C P D_{\mathrm{PN}}$. Third, data on speciation of Nocardia spp. is being revised with 16sRNA studies and our data is currently not available. It is well described that extensive discrepancy between biochemical testing and 16sRNA testing occurs and leads to re-speciation. ${ }^{19}$ Fourth, most of the cases of PN $(22 / 32,68.75 \%)$ in the current series were related to CPD; this is possibly because of high index of suspicion in our unit and the absence of hemato-oncology and organ transplant specialty service till 2016 in our hospital. Finally, the absence of spirometry reports for the five patients who died may have lead to over-estimation of values in the $A E-C P D_{P N}$ arm. As has been described, $29 \%$ were diagnosed with CPD when they presented with AE-CPD and it was not always feasible to do spirometry.

\section{Conclusion}

In conclusion, $\mathrm{PN}$ is a rare cause of $\mathrm{AE}-\mathrm{CPD}$ and can be recognized by a longer symptom duration, leukocytosis, extensive consolidation and cavitation. Early recognition is important, given the high shortterm mortality. $A E-C D_{P N}$ is independently associated with longer duration of hospital stay and mechanical ventilation. Respiratory failure requiring oxygen, NIPPV and mechanical ventilation is associated with mortality in $\mathrm{AE}-\mathrm{CPD}_{\mathrm{PN}}$.

\section{References}

1. Global Initiative for Chronic Obstructive Lung Disease (GOLD). Global Strategy for the Diagnosis, Management and Prevention of chronic obstructive pulmonary disease: 2018 Report. 2018. Accessed 20/7/2018.

2. Ko FW, Chan KP, Hui DS, Goddard JR, Shaw JG, Reid DW, et al. Acute exacerbation of COPD. Respirology. 2016;21(7):1152-1165.

3. Menendez R, Cordero PJ, Santos M, Gobernado M, Marco V.Pulmonary infection with Nocardia species: a report of 10 cases and review. Eur Respir J. 1997;10(7):1542-1546.

4. Garcia-Bellmunt L, Sibila O, Solanes I, Sanchez-Reus F, Plaza V. Pulmonary nocardiosis in patients with COPD: characteristics and prognostic factors. Arch Bronconeumol. 2012;48(8):280-285.

5. Global Strategy for Asthma Management and Prevention, Global Initiative for Asthma (GINA). 2018. Accessed 20-7-2018.

6. Travis WD, Costabel U, Hansell DM, King TE Jr, Lynch DA, Nicholson AG, et al. An official American Thoracic Society/European Respiratory Society statement: Update of the international multidisciplinary classification of the idiopathic interstitial pneumonias. Am J Respir Crit Care Med. 2013;188(6):733-748.

7. Miller MR, Hankinson J, Brusasco V, Burgos F, Casaburi R, Coates A, et al. Standardisation of spirometry. Eur Respir J. 2005;26(2):319-338.

8. Lerner PI. Nocardiosis. Clin Infect Dis. 1996;22(6):891-903. 
9. Continuous or nocturnal oxygen therapy in hypoxemic chronic obstructive lung disease: a clinical trial. Nocturnal Oxygen Therapy Trial Group. Ann Intern Med. 1980;93(3):391-398.

10. Ambrosioni J, Lew D, Garbino J. Nocardiosis: updated clinical review and experience at a tertiary center. Infection. 2010;38(2):89-97.

11. Lederman ER, Crum NF. A case series and focused review of nocardiosis: clinical and microbiologic aspects. Medicine (Baltimore). 2004;83(5):300-313.

12. Beaman BL, Beaman L. Nocardia species: host-parasite relationships. Clin Microbiol Rev. 1994;7(2):213-264.

13. Riviere F, Billhot M, Soler C, Vaylet F, Margery J. Pulmonary nocardiosis in immunocompetent patients: can COPD be the only risk factor? Eur Respir Rev. 2011;20(121):210-212.

14. Aide MA, Lourenco SS, Marchiori E, Zanetti G, Mondino PJ. Pulmonary nocardiosis in a patient with chronic obstructive pulmonary disease and bronchiectasis. J Bras Pneumol. 2008;34(11):985-988.
15. Anderson M, Kuzniar TJ. Pulmonary nocardiosis in a patient with chronic obstructive pulmonary disease-case report and literature review. Pneumonol Alergol Pol. 2012;80(6):565-569.

16. Castellana G, Grimaldi A, Castellana M, Farina C, Castellana G. Pulmonary nocardiosis in chronic obstructive pulmonary disease: $\mathrm{A}$ new clinical challenge. Respir Med Case Rep. 2016;18:14-21.

17. Khare V, Gupta P, Himanshu D, Kumar D. Emergence of co-trimoxazole resistant Nocardia brasiliensis causing fatal pneumonia. BMJ Case Rep. 2013;2013.

18. Franssen F. The semantics of COPD exacerbations. 2017. Accessed 20-7-2018.

19. Valdezate S, Garrido N, Carrasco G, Medina-Pascual MJ, Villalon P, Navarro AM, et al. Epidemiology and susceptibility to antimicrobial agents of the main Nocardia species in Spain. J Antimicrob Chemother. 2017;72(3):754-761. 